\title{
Identifying the Carrier of Martian Water in the Nakhla Meteorite
}

\author{
Martin Lee ${ }^{1}$ and Ian MacLaren ${ }^{2}$ \\ 1. School of Geographical and Earth Sciences, University of Glasgow. Glasgow, U.K. \\ 2. School of Physics and Astronomy, University of Glasgow, Glasgow, U.K.
}

A small proportion of the meteorites in our collections are from Mars, and they contain a wealth of information on the geological evolution of the planet. These rocks also have the potential to tell us much about the nature and history of Mars' atmosphere and hydrosphere. The most important group of Martian meteorites in this respect is the nakhlites. These igneous rocks are composed mainly of augite and olivine, and sample one or more lava flows or sills that formed 1300 million years ago [1]. In 1975 it was recognised that nakhlite olivine grains contain veins of hydrous compounds [2] and so they provide a unique opportunity to directly study Martian water and its interaction with the planet’s crust.

The most abundant water-bearing constituent of veins within olivine is a $\mathrm{Fe}$ - and Mg-rich silicate that is very fine grained and has proven difficult to identify. The first TEM study of this material concluded that it is "colloidal" [2], but subsequent research showed that it contains finely crystalline saponite, and occasionally also serpentine $[3,4]$. However, some of the more recent work has concluded that the veins are composed solely of a material that is described as "amorphous gel” [5]. We have sought to resolve this debate by characterising and identifying the carrier of Martian water in a SEM and (S)TEM study of the nakhlite meteorite Nakhla.

Nakhla fell in Egypt in 1911, and this study used a polished block of sample BM1913, 25. The veins of water-bearing Fe-Mg silicate were located by backscattered electron imaging and EDX analysis using a FEI Quanta 200F field-emission SEM. Wafers $~ 100 \mathrm{~nm}$ in thickness were cut from the veins using a FEI Nova Nanolab 200 FIB operated at $30 \mathrm{kV}$. The wafer that is the focus of the present study was further argon ion thinned using a Fischione Nanomill operated at $500 \mathrm{eV}$. Bright- and dark-field images were acquired using a FEI T20 operated at $200 \mathrm{kV}$. HAADF imaging, EELS and EDX mapping used a JEOL ARM200F equipped with a Gatan GIF Quantum ER electron energy loss spectrometer and a Bruker $60 \mathrm{~mm}^{2}$ SDDEDX spectrometer. The JEOL was mainly operated at $200 \mathrm{kV}$, and the nominal spot size for EDX and EELS mapping was $\sim 0.1 \mathrm{~nm}$ (although step sizes in mapping varied from $<1 \mathrm{~nm}$ to $>10 \mathrm{~nm})$.

The veins of water-bearing Fe-Mg silicate in Nakhla olivine grains are $3.5 \mu \mathrm{m}$ in width (Fig. 1). Most of them are oriented parallel to olivine (001), and their walls are finely serrated. Fe-Mg silicate is the sole constituent of some veins, whereas others also contain siderite, an Fe-rich carbonate. Siderite usually forms narrow selvages between the Fe-Mg silicate and olivine (Fig. 1), but may also cross-cut the Fe-Mg silicate veins. The Fe-Mg silicate is featureless in bright-field TEM images. SAED yields unbroken rings with d-spacings of 0.22 and $0.15 \mathrm{~nm}$ that are consistent with two-line ferrihydrite. Dark-field images made using the $0.22 \mathrm{~nm}$ ring show that it has been formed by scattering from crystals $\sim 6 \mathrm{~nm}$ in size that are distributed uniformly throughout the Fe-Mg silicate. HAADF STEM imaging reveals that the Fe-Mg silicate is composed of tightly packed $\sim 12 \mathrm{~nm}$ sized particles, each of which has a core-rim structure (Fig. 2). EDX and EELS mapping demonstrate that the cores are composed of Si and $\mathrm{O}$ whereas the shells are rich in $\mathrm{Mg}$ and $\mathrm{Fe}^{3+}$ (Fig. 2). Together these properties indicate that the Fe$\mathrm{Mg}$ silicate is composed of nanoparticles of opaline silica (amorphous $\mathrm{SiO}_{2} \cdot n \mathrm{H}_{2} \mathrm{O}$ ), each of which has a 
ferrihydrite shell. The siderite contains irregular patches that are enriched in $\mathrm{O}$ and $\mathrm{Fe}^{3+}$ and depleted with respect to $\mathrm{C}$. These findings indicate that the carbonates have been partially oxidised to goethite.

Our conclusion that opaline silica is the main carrier of Martian water in the Nakhla meteorite is consistent with the recent identification of deposits of opal at the surface of Mars by orbiters and rovers [6]. As these deposits are interpreted to have formed where hydrothermal water has met the planet's surface [6], we speculate the nakhlites sample the plumbing system of an ancient hot spring.

\section{References:}

[1] Borg L. and Drake M.J., Journal of Geophysical Research 110 (2005), E12S03.

[2] Ashworth J.R. and Hutchison R., Nature 256 (1975), p. 714-715.

[3] Gooding J.L. et al., Meteoritics 26 (1991), p. 135-143.

[4] Noguchi T. et al., Journal of Geophysical Research 114 (2009), E10004.

[5] Changela H.G. and Bridges J.C., Meteoritics and Planetary Science 45 (2011), p. 1847-1867.

[6] Skok J. R. et al., Nature Geoscience 3 (2010), p. 838-841.

[7] We thank the UK STFC for funding this work through grants ST/H002960/1, ST/K000942/1, and ST/L002167/1, and SUPA and the University of Glasgow for the provision of the JEOL ARM200F. We are also grateful to the Natural History Museum (London) for loan of the Nakhla sample.

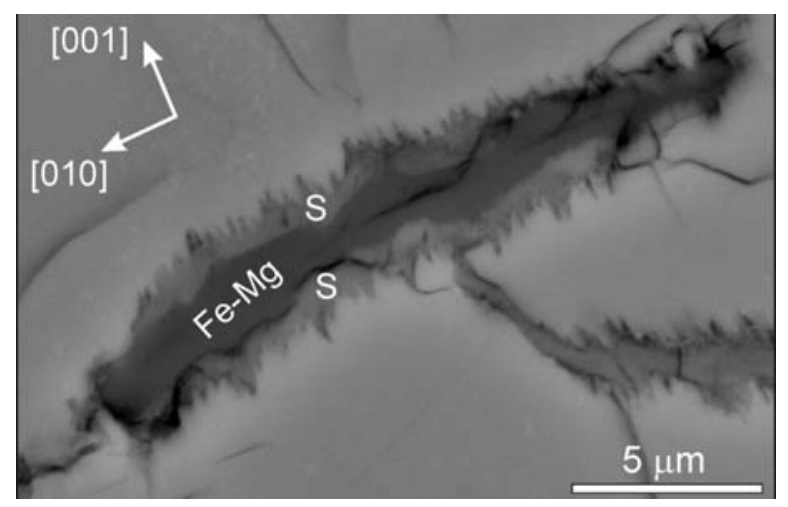

Figure 1. Backscattered electron SEM image of a Fe-Mg silicate vein within olivine. The Fe-Mg silicate (dark grey, labeled Fe-Mg) is flanked by selvages of siderite (S). The crystallographic orientation of olivine is indicated.
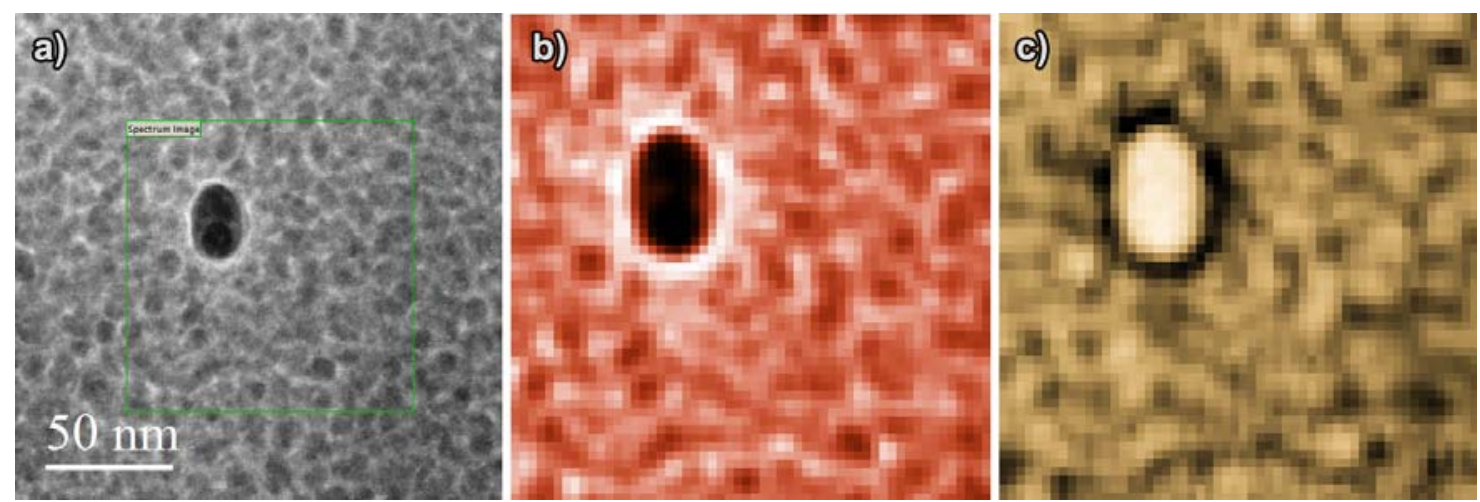

Figure 2. a) STEM-HAADF image showing a area of Fe-Mg silicate, with the area selected for analysis shown in the green box; b) Fe map from EELS at the $\mathrm{L}_{2,3}$ edge; c) Si map from EELS at the $\mathrm{L}_{2,3}$ edge. 